\title{
Influence of Er,Cr:YSGG Laser Irradiation on the Push-Out Bond Strength of Zirconia and Glass Fiber Posts with Radicular Dentin
}

\author{
Raneem S. Alofi $\mathbb{D},{ }^{1}$ Ibraheem F. Alshiddi $\mathbb{D}^{2}$, Yasser F. AlFawaz $\left(\mathbb{D},{ }^{1}\right.$ \\ Abdulaziz Alsahhaf $\mathbb{D}^{2}{ }^{2}$ Khulud Abdulrahman Al-Aali $\mathbb{D}^{3},{ }^{3}$ Tariq Abduljabbar $\mathbb{D}^{2,4}$ \\ and Fahim Vohra $\mathbb{D i D}^{2}$ \\ ${ }^{1}$ Department of Restorative Dental Sciences, College of Dentistry, King Saud University, Riyadh 11545, Saudi Arabia \\ ${ }^{2}$ Department of Prosthetic Dental Science, College of Dentistry, King Saud University, Riyadh 11545, Saudi Arabia \\ ${ }^{3}$ Department of Clinical Dental Sciences, College of Dentistry, Princess Nourah Bint Abdulrahman University, \\ Riyadh, Saudi Arabia \\ ${ }^{4}$ Research Chair for Biological Research in Dental Health, College of Dentistry, King Saud University, Riyadh 11545, Saudi Arabia
}

Correspondence should be addressed to Fahim Vohra; fvohra@ksu.edu.sa

Received 13 June 2019; Revised 27 August 2019; Accepted 31 August 2019; Published 9 October 2019

Academic Editor: Wen-Cheng Chen

Copyright (C) 2019 Raneem S. Alofi et al. This is an open access article distributed under the Creative Commons Attribution License, which permits unrestricted use, distribution, and reproduction in any medium, provided the original work is properly cited.

\begin{abstract}
Objective. This in vitro study was designed to evaluate the influence of an Er,Cr:YSGG laser on the bond strength of zirconia and glass fiber posts with root dentin. Materials and methods. Ninety extracted single-rooted human teeth were randomized into 6 groups ( $n=15$ /group) on the basis of different posts (zirconia/glass fiber) and Er,Cr:YSGG laser tips (axial and radial). Specimens were prepared for push-out testing with the help of a cutting machine; six slices ( 2 on each cervical, middle, and apical) of approximately $1 \mathrm{~mm}$ thickness were sectioned for all roots on a plane perpendicular to the long axis of the post. All specimens were placed into a universal testing machine with a defined $0.5 \mathrm{~mm} / \mathrm{min}$ crosshead speed until the maximum failure load was obtained. Results. The highest mean push-out bond strength of the glass fiber and zirconia groups was achieved with laser treatment. The highest push-out bond strength was achieved with the axial fiber tip $(7.63 \pm 1.22 \mathrm{MPa})$, and the lowest was achieved with a radial fiber tip of the glass fiber group $(6.98 \pm 0.96 \mathrm{MPa})$. ANOVA showed a statistically significant difference between the groups $(p=0.041)$. The mean push-out bond strength was found to be higher with an axial fiber tip for both cervical and apical segments in the glass fiber and zirconia groups $(p<0.05)$. The independent $t$-test resulted in the overall highest mean push-out bond strength in the apical segments $(p=0.026)$. Conclusion. Within the limits of the present in vitro research study, an enhancement in the push-out bond strength of resin cement, mainly in the cervical region of the root canal, was achieved after irradiation with an Er,Cr:YSGG laser using an axial fiber tip.
\end{abstract}

\section{Introduction}

Dental posts are used in cases where the tooth structure is extensively deteriorated and requires strong support [1]. The long-term success of endodontic-treated tooth depends on several factors including post surface/interface, root dentin, and the resin cement that helps to tether the post within the root structure [2]. The efficacy of bonding among the three components may aid in the distribution of forces along the root system [3]. Failure of any of these components may lead to improper stress distribution along the tooth structure owing to mastication [4]. Several techniques have been proposed in order to enhance the bond strength of glass fiber post and the dentine surface. As the glass fiber post does not directly bond with the resin surface, microretentive areas are created by roughening to increase the bond strength between the glass fiber and resin. These techniques include chemical roughening including the use of hydrogen peroxide and silane, and mechanical roughening including airborne particle abrasion with aluminum oxide or acid etching [5-7].

The demand for esthetic restorative materials has increased and led to the introduction of yttria-tetragonal zirconia polycrystalline (Y-TZP) ceramics. This dental material is widely used in the fabrication of core materials in 
fixed bridges, crowns, dental implant abutments, and endodontic posts [8-10]. However, there is a striking difference in the composition and physical properties of silica-based ceramics and zirconia, and acid etching cannot easily create micromechanical tags of resin cements. Therefore, other substitute methods warrant surface alterations in case of zirconia ceramics [11-13]. Several in vitro studies have researched the efficacy of different techniques including silica coating and surface modification using lasers [14-16].

Laser technology has been widely used in dental procedures [17-19]. In this regard, different wavelengths have been used to modify the surfaces of restorative materials in order to increase the bond strength. Data from previous studies suggest that laser irradiation enhances surface modification on dental posts, which greatly increases the bond strength with resin cements [20-22]. The laser therapy of a target dental material differs depending on the laser parameters used, such as wavelength. The in vitro data seeking to improve the adhesive resin cement-post-dentin interface warrant further investigation. Therefore, this in vitro study was designed to evaluate the influence of $\mathrm{Er}, \mathrm{Cr}$ : YSGG laser on the bond strength of zirconia and glass fiber posts with root dentin.

\section{Materials and Methods}

The experiment was performed with ninety maxillary and mandibular extracted single-rooted human teeth having at least $14 \mathrm{~mm}$ of root length, with their coronal aspect decoronated from the cemento-enamel junction. The selected teeth were then randomized into 6 groups $(n=15 /$ group) on the basis of different posts (zirconia/glass fiber) and Er,Cr:YSGG laser tips (axial and radial) as shown in Table 1 . The bond strength was evaluated using push-out tests for both posts and laser irradiation conditions.

The root canals of all teeth were performed using a crown-down technique from mechanical ProTaper Universal (Dentsply, Bellaigues, Switzerland) rotary files and irrigated with $2 \mathrm{~mL}$ of $2.5 \%$ sodium hypochlorite. A \#35 manual K file (Dentsply) was used as the master file. The root canals were irrigated using distilled water, and then filled with standardized gutta-percha points (Dentsply) and sealed using a root canal sealer with AH Plus (Dentsply, Konstanz, Germany). All treated roots were stored in a humid environment at $37^{\circ} \mathrm{C}$ for $24 \mathrm{~h}$.

A $10 \mathrm{~mm}$ glass fiber post (Postec plus \#3; Ivoclar, Schaan, Liechtenstein) was used in the study. With the help of a consecutive sequence of Gates Glidden with increasing diameter, the coronal gutta-percha was removed and the space was enlarged for easier placement. A low-speed bur was used to finish and shape the post space provided in the kit. Subsequently, $2 \mathrm{~mL} \mathrm{NaOCl}$ was used to irrigate the root canal and later neutralized by $5 \mathrm{~mL}$ of distilled water.

An Er,Cr:YSGG laser system (Waterlase; Biolase, San Clemente, CA) with a wavelength of $2780 \mathrm{~nm}$ and frequency rate of $20 \mathrm{~Hz}$ was used. The two types of laser fiber tips provided radial and axial irradiation. A preset water:air ratio of $37: 34 \%$ for the exchangeable axial fiber tip $(400 \mu \mathrm{m}$,
TABLE 1: General parameters of the studied groups.

\begin{tabular}{lccc}
\hline \multirow{2}{*}{ Study groups } & \multicolumn{3}{c}{ Experimental groups } \\
& Control & Axial fiber tip & Radial fiber tip \\
\hline Glass fiber posts & I & II & III \\
Zirconia posts & IV & V & VI \\
\hline
\end{tabular}

Biolase) was used. For the radial fiber tip, a $17 \mathrm{~mm}$ long sapphire endolase RTF3, $415 \mu \mathrm{m}$ Biolase was used. The laser parameters were: power, $1.2 \mathrm{~W}$; frequency, $15 \mathrm{~Hz}$; energy fluence, $59.14 \mathrm{~J} / \mathrm{cm}^{2}$; and pulse duration, $140 \mu \mathrm{s}$. The fiber tip was inserted inside the root canal till the apex and moved from the apical to the coronal direction with the average speed of $2 \mathrm{~mm} / \mathrm{s}$ for 5 times with $20 \mathrm{~s}$ interval to supply enough energy to the dentin tissue.

The surfaces of all posts were etched using 37\% phosphoric acid for $60 \mathrm{~s}$ and later rinsed with water, air-dried, coated with a layer of Monobond primer (Ivoclar, Schaan, Liechtenstein), and then again air-dried for $15 \mathrm{~s}$.

The zirconia and glass fiber posts were then cemented inside their respective post spaces with (test groups) and without laser irradiation (control group), which was carried out manually under pressure for 1-2 min. Light curing was performed on all the specimens for $60 \mathrm{~s}$ at a power density of $500 \mathrm{~mW} / \mathrm{cm}^{2}$ (Optilight plus; Gnatus, Ribeirão Preto, Brazil); the specimens were then stored in containers under maximum humidity at room temperature for $48 \mathrm{~h}$. For cementation, RelyX Unicem Aplicap (3M ESPE AG, Seefeld, Germany) capsules were activated (Aplicap Activator; 3M ESPE AG) and mixed in a high-frequency mixer for $20 \mathrm{~s}$. After the cleaning process, the cement was applied with the elongation tip, and the fiber post was settled.

The specimens were prepared for push-out testing. With the help of a cutting machine (Accutom 5; Struers, Cleveland, $\mathrm{OH}$ ), six slices ( 2 on each cervical, middle, and apical) of approximately $1 \mathrm{~mm}$ thickness were sectioned for all roots on the plane perpendicular to the long axis of the post. The bonding surface area of the two posts for each slice was computed according to the conical section:

$$
A=\pi(R+r) \sqrt{(R-r)^{2}+H^{2}},
$$

where $R=$ coronal post radius, $r=$ apical post radius, and $H=$ slice thickness.

All specimens were placed in a universal testing machine within a centralizing plate to ensure load application at the post center. Load was applied from the apical to cervical region, at a defined crosshead speed of $0.5 \mathrm{~mm} / \mathrm{min}$ until the maximum failure load was obtained. The push-out strength $(\sigma)$, defined in megapascals $(\mathrm{MPa})$, was derived from the following equation:

$$
\sigma=\frac{F}{A}
$$

where $F=$ force load at failure (Newton) and $A=$ conical surface area $\left(\mathrm{mm}^{2}\right)$.

Failure modes were determined by visually assessing fractured surfaces and then later confirmed using a stereo microscope (100x). Failure modes were divided and reported 
as either "adhesive-post" interface, "adhesive-dentin" interface, or "mixed" types of failure.

\section{Results}

Normality testing showed all the variables to be normally distributed after the Shapiro-Wilk test. The study groups without laser treatment were designated as I and IV for the glass fiber and zirconia posts, respectively. The axial fiber tips for both glass fiber and zirconia were designated as II and V, whereas III and VI were assigned to glass fiber and zirconia, respectively (Table 1). The highest mean push-out bond strength of glass fiber and zirconia posts was achieved with laser treatment. The highest push-out bond strength was achieved with an axial fiber tip $(7.63 \pm 1.22 \mathrm{MPa})$ and the lowest was achieved with a radial fiber tip in the glass fiber group $(6.98 \pm 0.96 \mathrm{MPa})$. ANOVA showed a statistically significant difference between the groups $(p=0.041)$ (Table 2). Table 3 presents the comparison of the push-out bond strength values among the groups based on the cervical, middle, and apical segments. The mean push-out bond strength was found to be higher with an axial fiber tip for the cervical and apical segments in both, glass fiber and zirconia groups $(p<0.05)$. The independent $t$-test resulted in the overall highest mean push-out bond strength in the apical segments than in other thirds of the root $(p=0.026)$. The middle third showed no statistically significant differences, either between the axial and radial fiber tips or between the glass fiber and zirconia posts $(p=0.832)$ (Table 3$)$. Nine failures were seen between the adhesive-dentin interface, while only two failures were seen at the adhesive-post interface. A total of four failures were mixed. Overall, the group with the smallest total number of failure modes was found in the glass fiber post, while the group with the largest number of failure modes was found in the control group (Table 4). The Weibull plot was computed using three Weibull parameters including the Weibull modulus, $10 \%$ and $63.2 \%$ failure expectation that analyzed differences between the push-out bond strength of the posts among different segments of the root dentin (Table 5). It is noted that the highest value for Weibull modulus was observed in the control group for glass fiber post and radial fiber tip application for the zirconia post, respectively. The Weibull plots of the push-out bond strength and three segments of the root dentin are illustrated in Figure 1. It is observed that the slope is steeper for only radial fiber tip application in the glass fiber posts than the slopes presented for other groups.

\section{Discussion}

This study aimed to evaluate the influence of an Er,Cr:YSGG laser on the bond strength of zirconia and glass fiber posts with root dentin. According to this study, the root system irradiated with Er,Cr:YSGG with an axial fiber tip application achieved the best push-out bond strength in both glass fiber and zirconia dental posts. The possible explanation for the best push-out bond strength could be the complete removal of unnecessary material from the root canal system and a strong bond between the resin cement
TABLE 2: Overall push-out bond strength values of the different post groups expressed in $\mathrm{MPa}( \pm \mathrm{SD})$.

\begin{tabular}{lccc}
\hline \multirow{2}{*}{ Study groups } & \multicolumn{3}{c}{ Experimental groups } \\
& Control & Axial fiber tip & Radial fiber tip \\
\hline Glass fiber posts & $6.09 \pm 0.94$ & $7.63 \pm 1.22^{*}$ & $6.98 \pm 0.96$ \\
Zirconia posts & $6.19 \pm 1.00$ & $7.41 \pm 1.03^{*}$ & $7.13 \pm 1.06$ \\
\hline *Statistically significant difference at $p<0.05$ compared between the \\
groups.
\end{tabular}

TABle 3: Push-out bond strength values of the cervical, middle, and apical segments $(\mathrm{MPa})( \pm \mathrm{SD})$.

\begin{tabular}{lccc}
\hline Groups & $\begin{array}{c}\text { Cervical } \\
\text { segment }\end{array}$ & $\begin{array}{c}\text { Middle } \\
\text { segment }\end{array}$ & $\begin{array}{c}\text { Apical } \\
\text { segment }\end{array}$ \\
\hline Glass fiber posts & & & \\
$\quad$ Axial & $7.01 \pm 1.21^{*}$ & $7.14 \pm 1.33$ & $7.72 \pm 1.99^{* \dagger}$ \\
$\quad$ Radial & $6.82 \pm 1.18$ & $7.31 \pm 1.09$ & $7.21 \pm 1.84$ \\
\hline Zirconia posts & & & \\
$\quad$ Axial & $7.49 \pm 1.88^{*}$ & $7.01 \pm 0.93$ & $7.88 \pm 1.92^{* \dagger}$ \\
$\quad$ Radial & $6.52 \pm 0.81$ & $7.09 \pm 0.09$ & $7.02 \pm 1.11$ \\
\hline Control group & $6.41 \pm 2.17$ & $6.14 \pm 0.74$ & $5.33 \pm 1.00$ \\
\hline
\end{tabular}

* Statistically significant results obtained by $t$-test at $p<0.05$ compared between axial and radial fiber tips. ${ }^{\dagger}$ Statistically significant results obtained by $t$-test at $p<0.05$ compared between each third of the segment.

TABle 4: Type of failure modes in each group.

\begin{tabular}{lcccc}
\hline Groups & $\begin{array}{c}\text { Root } \\
\text { segment }\end{array}$ & $\begin{array}{c}\text { Type of failure } \\
\text { Adhesive- } \\
\text { post }\end{array}$ & $\begin{array}{c}\text { Adhesive- } \\
\text { dentin }\end{array}$ & Mixed \\
\hline Glass fiber & Cervical & 0 & 1 & 0 \\
posts & Apical & 0 & 1 & 0 \\
\hline Zirconia posts & Cervical & 1 & 1 & 1 \\
& Apical & 0 & 1 & 0 \\
\hline Control & Cervical & 1 & 3 & 2 \\
group & Apical & 0 & 2 & 1 \\
\hline
\end{tabular}

TABLE 5: Mean push-out bond strength of each group together with the results from the Weibull statistical analysis.

\begin{tabular}{lccc}
\hline Group & $\beta$ & $\eta$ & B10 \\
\hline Group I & 127.61 & 6.12 & 6.01 \\
Group II & 54.68 & 7.71 & 7.39 \\
Group III & 30.43 & 7.1 & 6.59 \\
Group IV & 79.41 & 6.23 & 6.05 \\
Group V & 36.25 & 7.52 & 7.07 \\
Group VI & 112.52 & 7.17 & 7.02 \\
\hline
\end{tabular}

$\beta$ : Weibull modulus; $\mathrm{B} 10$ and $\eta$ indicate $10 \%$ and $63.2 \%$ failure expectation, respectively.

and the dentin surface. In addition, laser irradiation aids in the removal of the smear layer that helps in the exposure of dentinal tubules and enhancement of mechanical retention, by widely increasing the surface area [23]. Laser irradiation has been widely used for several purposes including disinfection of the dental material surface, improvement in wettability [24], and enhancement of the adhesion and bond strength of the adhesive interfaces [25]. 




FIGURE 1: Weibull plots for push-out bond strength and different segments of root dentin.

The results of the present study are in accordance with the previous in vitro studies [22]. A study that investigated the efficacy of Er,Cr:YSGG laser irradiation on the glass fiber post revealed that the bond strength increased after irradiation. Similarly, this in vitro study concluded that laser irradiation at different power settings of the Er,Cr:YSGG laser significantly enhanced the microbond strength of the post core compared with surfaces that did not undergo laser treatment [22].

Research indicates that the efficacy of laser irradiation in increasing the push-out bond strength differs with the use of different laser systems. The surface alteration of a laser-irradiated substrate mainly depends on the laser parameters along with the physical and chemical properties of the material [26]. In our study, the laser parameters were kept constant and the resin cement was employed in the standard manner to lute the zirconia and glass fiber posts. This allowed us to efficiently evaluate and compare the push-out bond strength along with minimizing the probability of bias.

This study also compared the bond strength along different regions of the root canal system. Notably, the bond strength increased in the cervical region of the root canals in the control group compared with the other two regions. This reduction in bond strength in the deeper regions of the root canal system may be attributed to the partial polymerization of the resin cement or an inconsistent adjustment of the dental posts [27]. In the present study, it is also noteworthy that the glass fiber and zirconia posts irradiated with the Er,Cr:YSGG laser revealed an increased bond strength in the apical region. This explains the small diameter of the dental post in the apical region. We hypothesize that an increased removal of the epoxy resin and uncovering of glass fibers and zirconia crystals led to the increased micromechanical retention and penetration of the resin cement, thus augmenting the bond strength.

The present study has some limitations such as the use of a single self-adhesive resin system for luting the dental posts. A comparison of the push-out bond strength after laser irradiation between different adhesive composites would provide the true efficacy of the postadhesive interface. Moreover, the present study did not evaluate the bacterial outcomes after laser therapy. The microbial load after laser irradiation would suggest whether the bacterial count hampers the overall efficacy of laser irradiation in increasing the push-out bond strength. Although a higher bond strength was observed for the zirconia and glass fiber posts, this was not verified with the use of scanning electron microscopy (SEM). The use of SEM would enable us to deeply elucidate the microcracks and shallow pits for micromechanical retention. Therefore, further studies are recommended in this regard. Furthermore, the calculation of bonding surface area may not be standardized and truly applicable on all teeth. This is explained by the various anatomical forms of the root dentin and that root surfaces not being in a perfectly similar cylindrical shape.

\section{Conclusion}

Within the limits of the present study, an enhancement in the push-out bond strength of resin cement, mainly in the cervical region of the root canal, was achieved after irradiation with an Er,Cr:YSGG laser using an axial fiber tip.

\section{Data Availability}

The statistical data used to support the findings of this study are included within the article.

\section{Conflicts of Interest}

The authors declare that they have no conflicts of interest.

\section{Acknowledgments}

The authors are grateful to the Deanship of Scientific Research, King Saud University for funding through Vice Deanship of Scientific Research Chairs, Research Chair for Biological Research in Dental Health.

\section{References}

[1] A. J. Qualtrough and F. Mannocci, "Tooth-colored post systems: a review," Operative Dentistry, vol. 28, no. 1, pp. 86-91, 2003.

[2] E. A. Bonfante, L. F. Pegoraro, M. F. de Góes, and R. M. Carvalho, "SEM observation of the bond integrity of fiber-reinforced composite posts cemented into root canals," Dental Materials, vol. 24, no. 4, pp. 483-491, 2008.

[3] F. Butz, A. M. Lennon, G. Heydecke, and J. R. Strub, "Survival rate and fracture strength of endodontically treated maxillary incisors with moderate defects restored with different postand-core systems: an in vitro study," The International Journal of Prosthodontics, vol. 14, no. 1, pp. 58-64, 2001. 
[4] C. S. D. M. Coelho, J. C. G. Biffi, G. R. D. Silva, A. Abrahão, R. E. Campos, and C. J. Soares, "Finite element analysis of weakened roots restored with composite resin and posts," Dental Materials Journal, vol. 28, no. 6, pp. 671-678, 2009.

[5] A. Balbosh and M. Kern, "Effect of surface treatment on retention of glass-fiber endodontic posts," The Journal of Prosthetic Dentistry, vol. 95, no. 3, pp. 218-223, 2006.

[6] T. Tian, J. K. H. Tsoi, J. P. Matinlinna, and M. F. Burrow, "Aspects of bonding between resin luting cements and glass ceramic materials," Dental Materials, vol. 30, no. 7, pp. e147-e162, 2014.

[7] F. Monticelli, R. Osorio, F. T. Sadek, I. Radovic, M. Toledano, and M. Ferrari, "Surface treatments for improving bond strength to prefabricated fiber posts: a literature review," Operative Dentistry, vol. 33, no. 3, pp. 346-355, 2008.

[8] M. Wolfart, F. Lehmann, S. Wolfart, and M. Kern, "Durability of the resin bond strength to zirconia ceramic after using different surface conditioning methods," Dental Materials, vol. 23, no. 1, pp. 45-50, 2007.

[9] R. G. Luthardt, O. Sandkuhl, and B. Reitz, "Zirconia-TZP and alumina-advanced technologies for the manufacturing of single crowns," The European Journal of Prosthodontics and Restorative Dentistry, vol. 7, no. 4, pp. 113-119, 1999.

[10] A. N. Cavalcanti, R. M. Foxton, T. F. Watson, M. T. Oliveira, M. Giannini, and G. M. Marchi, "Y-TZP ceramics: key concepts for clinical application," Operative Dentistry, vol. 34, no. 3, pp. 344-351, 2009.

[11] R. Luthra and P. Kaur, "An insight into current concepts and techniques in resin bonding to high strength ceramics," Australian Dental Journal, vol. 61, no. 2, pp. 163-173, 2016.

[12] M. B. Blatz, A. Sadan, J. Martin, and B. Lang, "In vitro evaluation of shear bond strengths of resin to densely-sintered high-purity zirconium-oxide ceramic after long-term storage and thermal cycling," The Journal of Prosthetic Dentistry, vol. 91, no. 4, pp. 356-362, 2004.

[13] T. Yilmaz-Savas, N. Demir, A. N. Ozturk, and H. S. Kilic, "Effect of different surface treatments on the bond strength of lithium disilicate ceramic to the zirconia core," Photomedicine and Laser Surgery, vol. 34, no. 6, pp. 236-243, 2016.

[14] F. Ahrari, A. Boruziniat, and M. Alirezaei, "Surface treatment with a fractional $\mathrm{CO} 2$ laser enhances shear bond strength of resin cement to zirconia," Laser Therapy, vol. 25, no. 1, pp. 19-26, 2016.

[15] D. Ö. Dede, M. Yenisey, N. Rona, and F. Ö. Dede, "Effects of laser treatment on the bond strength of differently sintered zirconia ceramics," Photomedicine and Laser Surgery, vol. 34, no. 7, pp. 276-283, 2016.

[16] S. Kasraei, L. Rezaei-Soufi, B. Heidari, and F. Vafaee, "Bond strength of resin cement to CO2 and Er:YAG laser-treated zirconia ceramic," Restorative Dentistry \& Endodontics, vol. 39, no. 4, pp. 296-302, 2014.

[17] Z. Akram, T. Abduljabbar, F. Vohra, and F. Javed, "Efficacy of low-level laser therapy compared to steroid therapy in the treatment of oral lichen planus: a systematic review," Journal of Oral Pathology \& Medicine, vol. 47, no. 1, pp. 11-17, 2018.

[18] Z. Akram, T. Abduljabbar, S. Sauro, and U. Daood, "Effect of photodynamic therapy and laser alone as adjunct to scaling and root planing on gingival crevicular fluid inflammatory proteins in periodontal disease: a systematic review," Photodiagnosis and Photodynamic Therapy, vol. 16, pp. 142-153, 2016.

[19] Z. Akram, F. Vohra, and F. Javed, "Low-level laser therapy as an adjunct to connective tissue graft procedure in the treatment of gingival recession defects: a systematic review and meta-analysis," Journal of Esthetic and Restorative Dentistry, vol. 30, no. 4, pp. 299-306, 2018.

[20] K. Bitter, J. Noetzel, C. Volk, K. Neumann, and A. M. Kielbassa, "Bond strength of fiber posts after the application of erbium: yttrium-aluminum-garnet laser treatment and gaseous ozone to the root canal," Journal of Endodontics, vol. 34, no. 3, pp. 306-309, 2008.

[21] H. Arslan, C. Barutcigil, C. B. Yllmaz, K. T. Ceyhanl, and H. S. Topcuoglu, "Push-out bond strength between composite core buildup and fiber-reinforced posts after different surface treatments," Photomedicine and Laser Surgery, vol. 31, no. 7, pp. 328-333, 2013.

[22] S. Kurtulmus-Yilmaz, E. Cengiz, O. Ozan, S. Ramoglu, and H. G. Yilmaz, "The effect of Er,Cr:YSGG laser application on the micropush-out bond strength of fiber posts to resin core material," Photomedicine and Laser Surgery, vol. 32, no. 10, pp. 574-581, 2014.

[23] R. Guidotti, E. Merigo, C. Fornaini, J.-P. Rocca, E. Medioni, and P. Vescovi, "Er:YAG 2,940-nm laser fiber in endodontic treatment: a help in removing smear layer," Lasers in Medical Science, vol. 29, no. 1, pp. 69-75, 2014.

[24] A. Usumez, O. Inan, and F. Aykent, "Bond strength of a silicone lining material to alumina-abraded and lased denture resin," Journal of Biomedical Materials Research, vol. 71B, no. 1, pp. 196-200, 2004.

[25] A. Wilson, I. Jones, F. Salamat-Zadeh, and J. F. Watts, "Laser surface modification of poly(etheretherketone) to enhance surface free energy, wettability and adhesion," International Journal of Adhesion and Adhesives, vol. 62, pp. 69-77, 2015.

[26] D. J. Coluzzi, "Fundamentals of dental lasers: science and instruments," Dental Clinics of North America, vol. 48, no. 4, pp. 751-770, 2004

[27] A. R. Tuncdemir, C. Yıldırım, F. Güller, E. Özcan, and A. Usumez, "The effect of post surface treatments on the bond strength of fiber posts to root surfaces," Lasers in Medical Science, vol. 28, no. 1, pp. 13-18, 2013. 


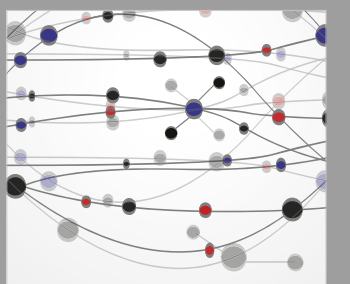

The Scientific World Journal
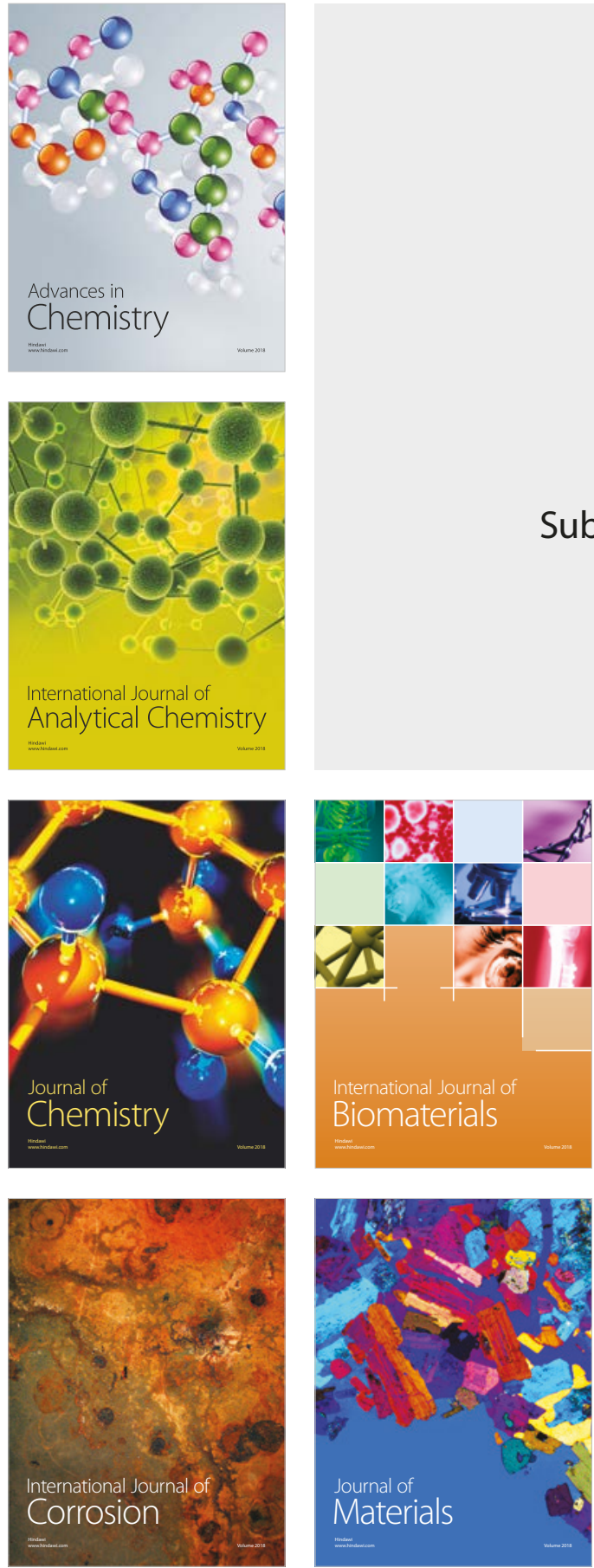

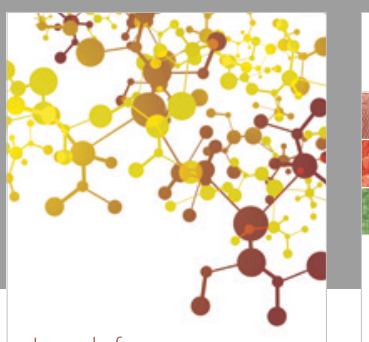

Journal of

Applied Chemistry




Scientifica

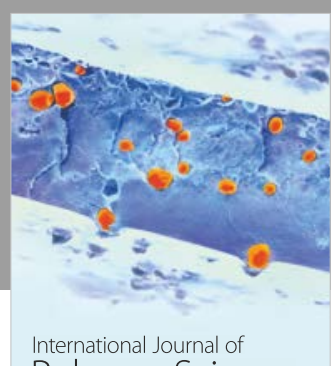

Polymer Science

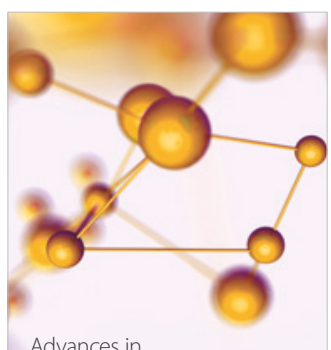

Physical Chemistry
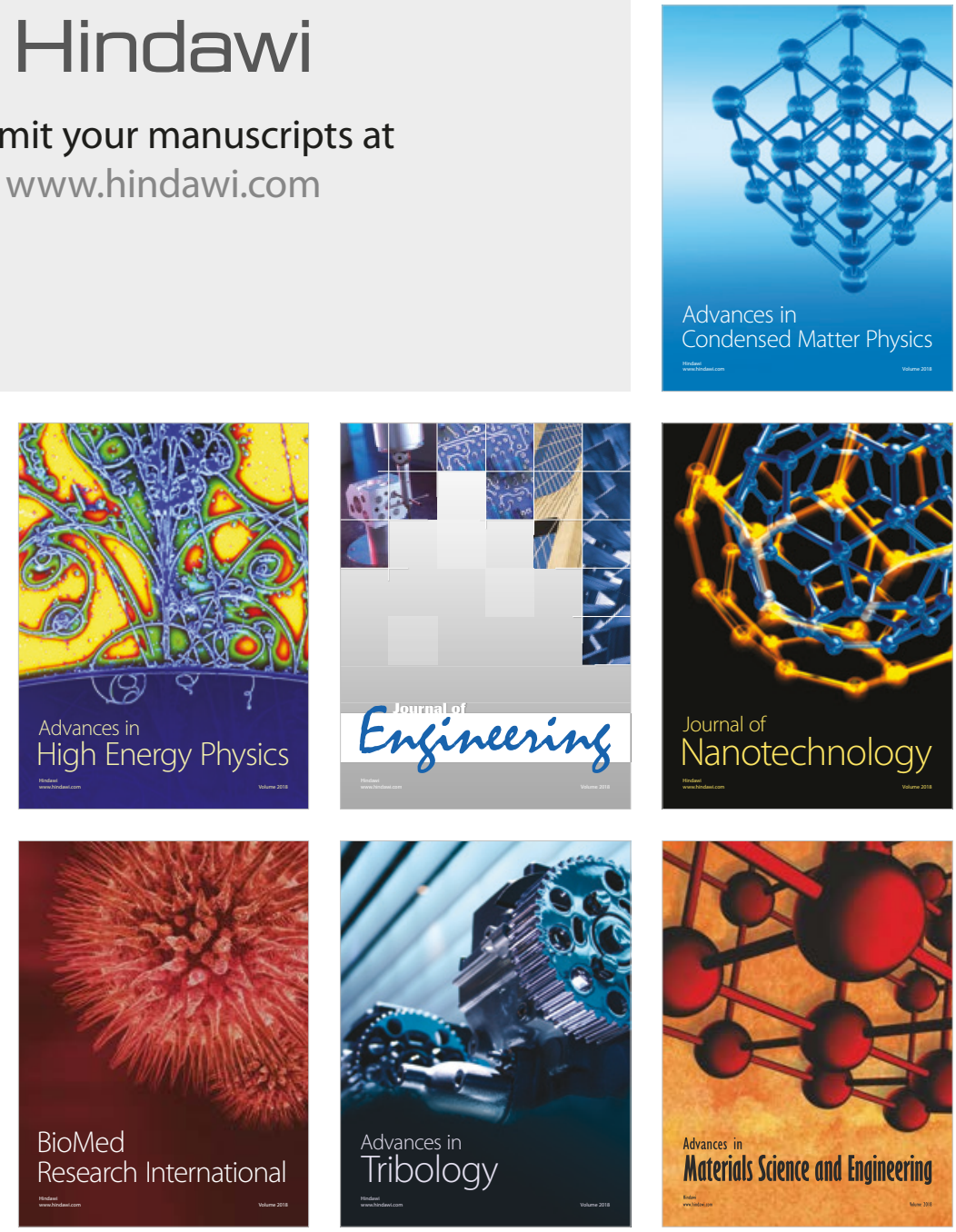